\title{
Crohn's appendicitis
}

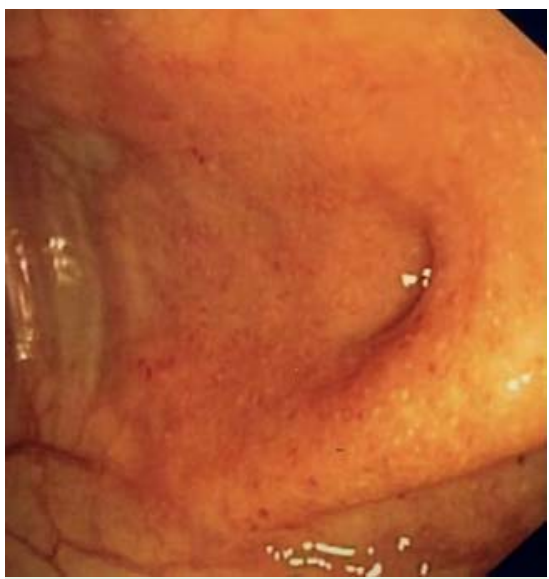

Fig. 1 Endoscopic appearance of Crohn's appendicitis. There is marked inflammation of the appendiceal foramen and the colonic mucosa surrounding the appendiceal foramen. Diffuse erosions are also seen, with normal appearance of the remaining cecal mucosa (on the left of the image).

In September 2009, a 43-year-old woman underwent colonoscopy for investigation of recurrent pain in the lower right abdominal quadrant. She also had recurrent diarrhea (three to four movements/day) with dark blood. After exclusion of intestinal infection and parasitic infestation, colonoscopy with retrograde ileoscopy was carried out. Endoscopy showed normal appearance of the colon and the last $20 \mathrm{~cm}$ of the ileum, however, the mucosa in the periappendiceal region and appendiceal foramen was inflamed, with diffuse erosions and complete loss of the vascular pattern ( Fig. 1).

The cecal mucosa was normal, with no lesions and a normal vascular pattern (৫ Fig. 1). Histological examination revealed massive transmucosal lymphomonocytic and granulocytic infiltrates, extending into the submucosal layer. Glandular distortion, lymphoid follicles, and noncaseous granulomas were also present $(\bullet$ Fig. 2).

The histological specimens from the terminal ileum and from other colonic regions were normal. The patient also underwent

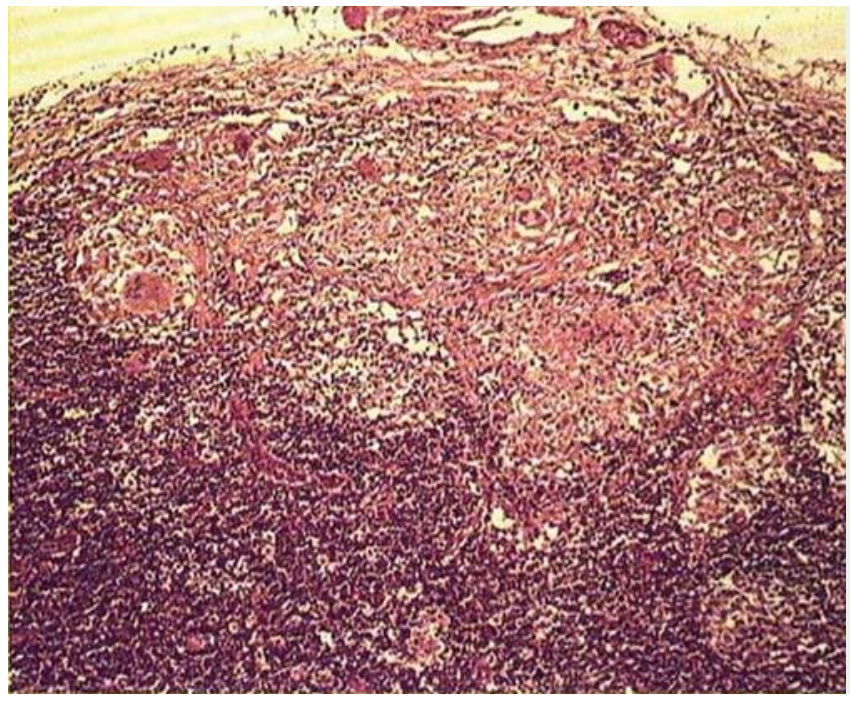

Fig. 2 Histological section showing marked transmucosal inflammatory infiltration, also involving the submucosal layer. Two noncaseous granulomas are present in the center of the image, under the epithelial layer.

small-bowel video capsule endoscopy but this did not reveal any lesion in the ileum. On the other hand, intestinal ultrasound and abdominal computed tomography confirmed the presence of inflammation limited to the appendiceal region. A diagnosis of Crohn's appendicitis was therefore proposed. The patient was successfully treated with budesonide $9 \mathrm{mg} /$ day, with complete disappearance of the symptoms within 2 weeks. At present (November 2009) the patient is still under treatment with budesonide $6 \mathrm{mg} / \mathrm{day}$, and she remains symptom-free.

Isolated appendicitis is a rare presentation of Crohn's disease [1]. In most cases the terminal ileum, or at least the cecal region, is also involved [2]. This disease should be suspected in patients with recurrent bloody stools with normal appearance of the colon, and colonoscopy may be helpful in detecting appendiceal and periappendiceal lesions [3].

\section{Endoscopy_UCTN_Code_CCL_1AD_2AD}

\footnotetext{
A. Tursi ${ }^{1}$, A. Penna ${ }^{2}$

1 Gastroenterology Service, ASL BAT, Andria (BAT), Italy

2 Division of Gastroenterology,

"M. Sarcone" Hospital, Terlizzi (BA), Italy
}

\section{References}

1 Vanek VW, Spiros G, Awad M. Isolated Crohn's disease of the appendix. Two cases reports and a review of the literature. Arch Surg 1988; 123: 85-87

2 Ripolles T, Martinez MJ, Morote V, Errando J. Appendiceal involvement in Crohn's disease. Gray-scale sonography and color Doppler flow features. AJR Am J Roentgenol 2006; 186: 1071 - 1078

3 Lima SE Jr, Speranzini MB, Guiro MP. Isolated Crohn's disease of the appendix as a source of enterorrhagia [Article in Portuguese]. Arq Gastroenterol 2004; 41: 60-63

Bibliography

DOI $10.1055 / \mathrm{s}-0029-1243872$

Endoscopy 2010; 42: E84

(c) Georg Thieme Verlag KG Stuttgart - New York . ISSN 0013-726X

\section{Corresponding author}

\section{A. Tursi, MD}

Servizio di Gastroenterologia Territoriale

ASL BAT

Via Torino 49

70031 Andria (BAT)

Italy

Fax: +39-883-551094

antotursi@tiscali.it 